\title{
CrónICA
}

\section{APICE INICIA OFICIALMENTE SUS ACTIVIDADES}

La Agencia de Acreditación de Programas y Centros Formadores de Especialistas (APICE) es un organismo privado, sin fines de lucro, que a comienzos de 2009 fue autorizada por la Comisión Nacional de Acreditación (CNA) para pronunciarse sobre la acreditación de los 238 programas que hoy ofrecen 12 Escuelas de Medicina del país. Ciento treinta y nueve de ellos forman especialistas en especialidades primarias y 89 en especialidades derivadas.

APICE nació por iniciativa de la Asociación de Facultades de Medicina (ASOFAMECH), con el propósito de ajustar el proceso de acreditación vigente desde 1980 a las disposiciones de la ley de Aseguramiento de la Calidad de la Enseñanza Superior, promulgada en octubre de 2006.

A esta iniciativa se sumaron las Sociedades Científicas de la Medicina Chilena agrupadas en ASOCIMED, el Colegio Médico de Chile y la Academia de Medicina del Instituto de Chile.

Cada una de estas 4 instituciones tiene representantes en el Directorio de APICE, que preside el Dr. Andrés Heerlein.

A fines de septiembre pasado la CNA aprobó los Criterios de Evaluación de Programas de Postítulo en Medicina, documento de carácter general, aplicable para la acreditación de cualquier programa de formación de especialistas y el (o los) centros asistenciales en que éste se realiza.
A estos criterios generales se agregan los requisitos particulares de cada especialidad que están siendo publicados en www.apicechile.cl.

Con estos documentos APICE se encuentra en condiciones de iniciar el proceso de acreditación, en el que ya se han inscrito 17 programas provenientes de 4 Escuelas de Medicina.

$\mathrm{Al}$ iniciar sus actividades, APICE agradece la generosa ayuda de las instituciones que le dieron origen y en particular a los doctores Octavio Enríquez, ex decano de la Facultad de Medicina de la Universidad de Concepción, actual Vicepresidente del Colegio Médico de Chile y miembro del Consejo de la CNA, quien jugó un rol decisivo en la aprobación de los criterios generales de evaluación arriba mencionados; y al Dr. Carlos Toro, ex Secretario Ejecutivo de APICE, cuya destacada y paciente labor fue tan importante para la organización de esta Agencia Acreditadora.

APICE nació de las instituciones más representativas de la medicina chilena y se encuentra a su servicio. Contamos con la excelente voluntad de los miembros de su Directorio, de sus Consejos y de numerosos Pares Evaluadores para ofrecer a nuestro sistema universitario un nuevo ejemplo de organización al servicio del bien común.

\author{
Dr. Vicente Valdivieso Dávila \\ Secretario Ejecutivo \\ APICE
}

